\title{
Rapid analysis of pyrethroid insecticides in aquaculture seawater samples via membrane-assisted solvent extraction coupled with gas chromatography-electron capture detection
}

\author{
X. Z. Shi, $\uparrow^{* a}$ S. Q. Song, $\dagger^{b}$ A. L. Sun, ${ }^{a}$ J. H. Liu, ${ }^{a}$ D. X. Li $^{a}$ and J. Chen ${ }^{a}$ \\ Received 27th August 2011, Accepted 21st October 2011 \\ DOI: $10.1039 / \mathrm{c} 1 \mathrm{an} 15782 \mathrm{e}$
}

\begin{abstract}
A simple, efficient, and environmentally friendly membrane-assisted solvent extraction (MASE) method for the extraction and preconcentration of six pyrethroid insecticides from aquaculture seawater samples followed by gas chromatography-electron capture detection (GC-ECD) was successfully proposed. The operating conditions for MASE, such as the extraction solvent, solvent volume, $\mathrm{NaCl}$ concentration, stirring rate, extraction time, and temperature, were optimized.

Compared to conventional Florisil-solid phase extraction (SPE), higher extraction recoveries $(85.9 \%$ to $105.9 \%$ ) of three spiked levels of the six pyrethroid pesticides in aquaculture seawater were obtained using MASE, and the RSD values were lower than 7.9\%. The limits of detection (LOD, signal-to-noise ratio $(\mathrm{S} / \mathrm{N})=3$ ) and quantification ( $\mathrm{LOQ}, \mathrm{S} / \mathrm{N}=10$ ) were in the range of $0.037-0.166$ and $0.12-0.55 \mu \mathrm{g}$ $\mathrm{L}^{-1}$, respectively. The results demonstrate the excellent applicability of the MASE method in analyzing the six pyrethroid pesticides in aqueous samples. The proposed method exhibited a high potential for routine monitoring analysis of pyrethroid insecticides in seawater samples.
\end{abstract}

\section{Introduction}

Pyrethroid insecticides are broad-spectrum, high-efficiency insecticides widely used in controlling parasites and predators of aquaculture products. ${ }^{1,2}$ They enter aquatic environments either through direct application or runoff. Pyrethroid insecticides have a high potential to bioaccumulate in aquatic organisms and confer high toxicity to aquatic life and human health. ${ }^{3,4}$ Therefore, to protect the safety of aquaculture products and human health, sensitive, high enrichment capacity, convenient, and environmentally friendly analytical methods are required to monitor pyrethroid insecticide levels in seawater samples.

Novel sample purification and enrichment procedures as well as advanced analytical instruments such as gas chromatographytandem mass spectrometry (GC-MS) and gas chromatographyelectron capture detection (GC-ECD) are needed to develop the required methods..$^{5-7}$ GC-ECD, with its sufficient sensitivity and selectivity for most pyrethroid insecticides as well as lower costs compared to GC-MS or high performance liquid

${ }^{a}$ Faculty of Life Science and Biotechnology, Key Laboratory of Applied Technology of Marine Biology, Ministry of Education, Ningbo University, 818 Fenghua Road, Ningbo, 315211, P.R. China. E-mail: sxzsal78@yahoo.com.cn; Fax: +86-574-87608347; Tel: +86-57487600551

${ }^{b}$ Laboratory of Food Analysis, Faculty of Pharmaceutical Sciences, Ghent University, Harelbekestraat 72, 9000 Ghent, Belgium

$\uparrow$ These authors contributed equally to this work. chromatography-mass spectrometry (HPLC-MS), is usually employed. ${ }^{8}$ Furthermore, because of the typically low concentrations of pyrethroid insecticides in aqueous samples, the sample pretreatment approach, such as liquid-liquid extraction (LLE), ${ }^{9}$ solid-phase extraction (SPE), ${ }^{10}$ stir bar sorptive extraction (SBSE), ${ }^{11}$ solid-phase microextraction (SPME), and liquidphase microextraction (LPME), ${ }^{12,13}$ are now commonly adopted. LLE requires a long extraction time and high organic solvent consumption and is difficult to automate. ${ }^{14}$ Although SPE techniques are easier to automate compared with LLE, a series of cartridge drying and conditioning are required. SBSE, SPME, and LPME are simple methods and involve lower organic solvent consumption. However, the strict experimental control and long equilibrium times limit their application. ${ }^{15,16}$

At present, the membrane extraction method has become increasingly popular in aqueous sample preparation because of low solvent consumption, convenience, and suitability for automation. Membrane-assisted solvent extraction (MASE), which has been previously reported by Hauser et al. ${ }^{17}$ is a promising technique for aqueous sample preparation. The MASE device was developed using a dense polypropylene membrane bag attached to a metal funnel with a Teflon ring, and hexane or cyclohexane was generally used as the acceptor phase. Thus, a combination of MASE and GC-ECD or GC-MS is convenient and suitable for automation. This combination has been successfully applied to the determination of organic compounds, such as organophosphorus pesticides, hydrocarbon contamination, and phenols, in different aqueous matrices. ${ }^{18-20}$ 
In the current study, the operating conditions of MASE, including the extraction solvent, solvent volume, sodium chloride $(\mathrm{NaCl})$ concentration, stirring rate, extraction time, and temperature, as well as the enrichment of pyrethroid insecticides, were optimized and validated. In addition, the modern and environmentally friendly enrichment techniques of MASE were coupled with GC-ECD and successfully applied to the trace determination of pyrethroid insecticides in aquaculture seawater samples.

\section{Experimental}

\section{Chemicals}

Fenvalerate (FEN), deltamethrin (DEL), cypermethrin (CYP), cyfluthrin (CYF), phenothrin (PHE), and bifenthrin (BIF) (Fig. 1) were purchased from Dr Ehrenstorfer GmbH (Augsburg, Germany). $\mathrm{NaCl}$ and acetonitrile were purchased from the China National Pharmaceutical Group Corporation (Shanghai, China). HPLC grade hexane, acetone, and cyclohexane were obtained from Fisher Scientific Co. (USA). All other reagents were of analytical grade. MASE membrane bags and accessories were supplied by Gerstel (Mülheim, Germany). Standard solutions (500 $\mathrm{mg} \mathrm{L}^{-1}$ ) of FEN, DEL, CYP, CYF, PHE, and BIF were prepared in acetone. A $10 \mathrm{mg} \mathrm{L}^{-1}$ dilute standard in acetone was prepared weekly.

\section{Sample preparation}

The aquaculture seawater samples were obtained from the local aquaculture sea area and collected in glass bottles, which were transported to the laboratory at $4{ }^{\circ} \mathrm{C}$. The seawater samples were filtered through $0.45 \mu \mathrm{m} \mathrm{GF} / \mathrm{C}$ (Whatman, $25 \mathrm{~mm}$ diameter) filters. Prior to the experiments, the seawater samples were examined via GC-ECD to confirm the absence of detectable pyrethroid insecticides.<smiles>CC(C)C(C(=O)OC(C#N)c1cccc(Oc2ccccc2)c1)c1ccc(Cl)cc1</smiles><smiles>CC1(C)C(C=C(Br)Br)C1C(=O)OC(C#N)c1cccc(Oc2ccccc2)c1</smiles>

DEL<smiles>Cc1c(COC(=O)C2C(C=C(Cl)C(F)(F)F)C2(C)C)cccc1-c1ccccc1</smiles>

\section{Instrumentation and analytical conditions}

A GC-2010 gas chromatograph (Shimadzu, Japan) equipped with a ${ }^{63} \mathrm{Ni}$ electron capture detector (ECD) and a split/splitless capillary column injector was used for the analysis. Separation was performed on a Supel SPB-5 $(30 \mathrm{~m} \times 0.25 \mathrm{~mm}$ I.D. $\times 0.25 \mu \mathrm{m}$ film thickness) capillary column. Nitrogen $\left(\mathrm{N}_{2}\right)$ was used as the carrier and makeup gas at a flow rate of $1.0 \mathrm{~mL} \mathrm{~min}^{-1}$ (constant flow). The oven temperature program was as follows: from $240^{\circ} \mathrm{C}$ for $3 \mathrm{~min}$ to $290{ }^{\circ} \mathrm{C}$ held for $5 \mathrm{~min}$, at a rate of $5{ }^{\circ} \mathrm{C} \mathrm{min}^{-1}$. The ECD temperature was set at $320^{\circ} \mathrm{C}$. The standard solutions and sample extracts $(1.0 \mu \mathrm{L})$ were injected using the split mode with a ratio of $30: 1$ at an injection temperature of $240{ }^{\circ} \mathrm{C}$.

\section{MASE}

The membrane and device of MASE is produced by Gerstel (Mülheim, Germany). Prior to use, the MASE membrane was sequentially conditioned with $10 \mathrm{~mL}$ hexane and hexane:acetone $(9: 1, \mathrm{v} / \mathrm{v})$ at room temperature for $2 \mathrm{~h}$. The extraction vial was a conventional $20 \mathrm{~mL}$ headspace vial filled with $15.0 \mathrm{~mL} \mathrm{NaCl}-$ saturated seawater samples. The membrane bag was filled with $0.75 \mathrm{~mL}$ hexane:acetone $(9: 1, \mathrm{v} / \mathrm{v})$ and agitated at $600 \mathrm{rpm}$ for $60 \mathrm{~min}$ at $40{ }^{\circ} \mathrm{C}$. After agitation, the organic phase in the membrane bag was transferred into a $2.0 \mathrm{~mL}$ autosampler vial, which was placed in the GC-ECD autosampler for analysis.

\section{Florisil-SPE}

A commonly applied SPE based on Florisil sorbent materials (6 mL, $200 \mathrm{mg}$, CNWBOND, Germany) was investigated for pyrethroid insecticide analysis. ${ }^{21}$ The Florisil-SPE cartridges were sequentially conditioned with $5.0 \mathrm{~mL}$ methanol and $3.0 \mathrm{~mL}$ water. The aquaculture seawater was filtered through $0.45 \mu \mathrm{m}$ filters, and the filtrate $(10.0 \mathrm{~mL})$ was loaded onto the Florisil-SPE cartridges<smiles>CC1(C)C(C=C(Cl)Cl)C1C(=O)OC(C#N)c1cccc(Oc2ccccc2)c1</smiles><smiles>CC1(C)C(C=C(Cl)Cl)C1C(=O)OC(C#N)c1ccc(F)c(Oc2ccccc2)c1</smiles>

CYF<smiles>CC(C)=CC1C(C(=O)OCc2cccc(Oc3ccccc3)c2)C1(C)C</smiles>

PHE

Fig. 1 Chemical structures for pyrethroid insecticides. 
at a flow rate of $1.0 \mathrm{~mL} \mathrm{~min}^{-1}$. The SPE cartridges were then washed with $3 \times 1 \mathrm{~mL}$ water and dried for 10 min under a $\mathrm{N}_{2}$ atmosphere. Elution was performed using $8.0 \mathrm{~mL}$ diethyl ether: acetone:hexane $(2: 2: 1, \mathrm{v} / \mathrm{v} / \mathrm{v})$ at a flow rate of $2.0 \mathrm{~mL} \mathrm{~min}^{-1}$. The elution fractions were dried under a stream of $\mathrm{N}_{2}$. The residue was redissolved in $1.0 \mathrm{~mL}$ isooctane:acetone $(9: 1, \mathrm{v} / \mathrm{v})$ and filtered through a $0.22 \mu \mathrm{m}$ nylon filter for the subsequent GC-ECD analysis.

\section{Method validation}

For the validation of the reliability of the developed method, a linearity using different concentrations of pyrethroid insecticides in the range of $1.0-10.0 \mu \mathrm{g} \mathrm{L}^{-1}$ for FEN, DEL, CYP, CYF, BIF, and $10.0-100.0 \mu \mathrm{g} \mathrm{L}^{-1}$ for PHE was prepared. The recovery study was conducted by analyzing seawater samples spiked with 2.5, 5.0, and $7.5 \mu \mathrm{g} \mathrm{L}^{-1}$ of FEN, DEL, CYP, CYF, BIF, and 25, 50, and $75 \mu \mathrm{g} \mathrm{L}^{-1}$ of PHE and the recovery was calculated by comparing the concentrations of the spiked solutions in the final seawater samples with the concentrations initially added to the samples. The precision of the method was determined by calculating the relative standard deviation (RSD) using three different membrane bags. The limit of detection (LOD) and limit of quantification (LOQ) for the MASE method were determined at signal-to-noise $(\mathrm{S} / \mathrm{N})$ ratios of $3: 1$ and $10: 1$, respectively. All experiments were run in triplicate and each data point is the average value.

\section{Results and discussion}

\section{Optimization of the extraction parameters}

Membrane bag preconditioning. Before further application, the MASE membrane bag underwent a sequential preconditioning step using hexane and hexane:acetone $(9: 1, \mathrm{v} / \mathrm{v})$ to remove interfering compounds from the membrane materials that can be coextracted with the analytes. After extraction, the organic phase in the membrane bags was transferred into $2.0 \mathrm{~mL}$ vials and analyzed via GC-ECD to confirm the absence of detectable interferences. The parameters affecting the extraction efficiency of MASE, including solvent selection, solvent volume, extraction time, stirring rate, and extraction temperature, were then investigated.

Optimization of extraction solvent and times. As an acceptor solvent, the organic solvent should have a relatively low solubility in water to minimize losses and should be volatile for the convenient combination with GC-ECD during the MASE procedure. Furthermore, the highly lipophilic nature of pyrethroid insecticides has conferred them with fairly high hydrophobicity and low water solubility. Therefore, the use of hexane, cyclohexane, and their mixtures with acetone as acceptor phases for MASE were investigated.

A $15.0 \mathrm{~mL}$ seawater sample spiked with $10 \mu \mathrm{g} \mathrm{L}^{-1}$ each of the six pyrethroid insecticides was extracted with $0.75 \mathrm{~mL}$ of each of the solvents for $60 \mathrm{~min}$ at $25^{\circ} \mathrm{C}$, at a shaking speed of $600 \mathrm{rpm}$. Each sample was extracted three times. The results are shown in Fig. 2. The appropriate addition of the polar organic solvent acetone to the acceptor solvent obviously increased the extraction efficiency. In contrast, excess acetone, a water-miscible solvent, in the acceptor phase results in a change of the acceptor phase volume coupled with a significant decrease of reproducibility for the extraction. Furthermore, the highest recoveries of pyrethroid insecticides were acquired when the seawater samples were extracted three times with hexane:acetone $(9: 1, \mathrm{v} / \mathrm{v})$. However, the recoveries were relatively low when the seawater samples were extracted once with $0.75 \mathrm{~mL}$ hexane:acetone $(9: 1$, $\mathrm{v} / \mathrm{v})$, which greatly decreased the practicality and automation potential of MASE coupled with GC-ECD. Hence, improving the recoveries of the first MASE extraction is very important.
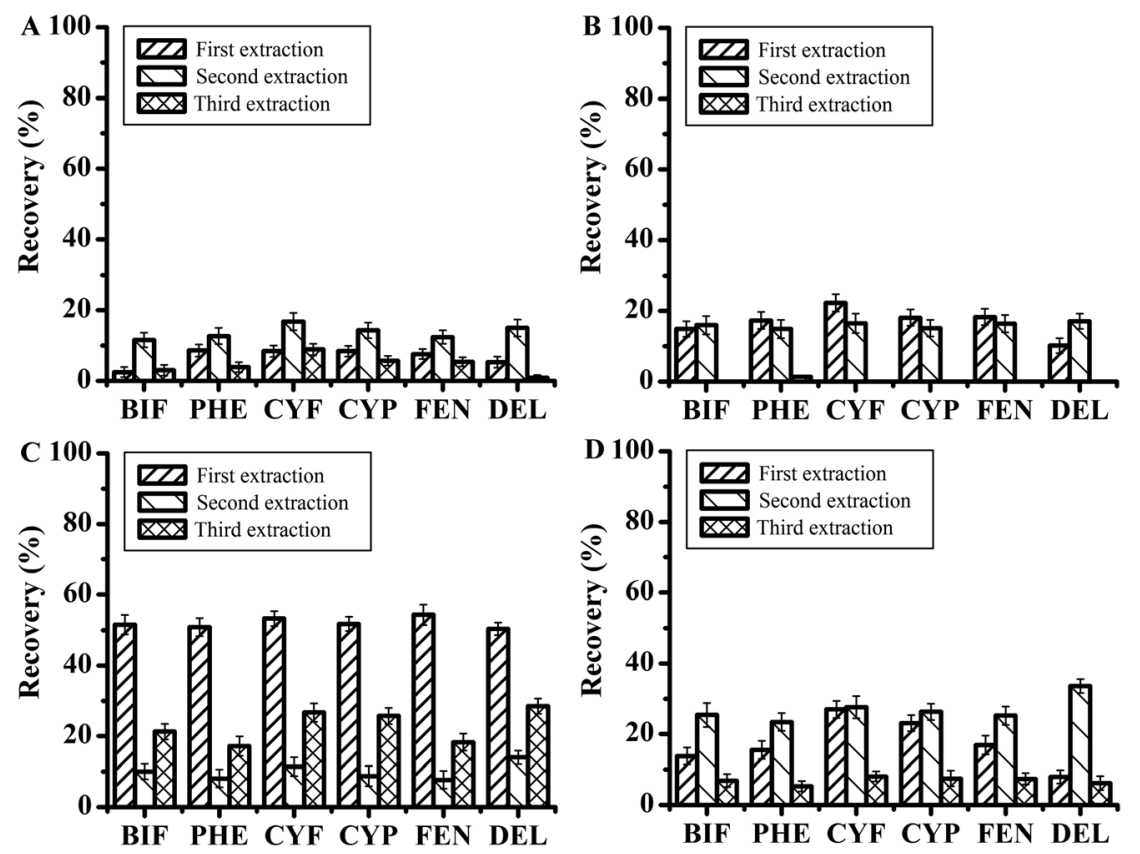

Fig. 2 Optimization of the extraction solvent and extraction time: (A) hexane; (B) cyclohexane; (C) hexane:acetone (9: 1, v/v); and (D) cyclohexane: acetone $(9: 1, \mathrm{v} / \mathrm{v})$. Analyte concentration: $10 \mu \mathrm{g} \mathrm{L}{ }^{-1}$; extraction conditions: $60 \mathrm{~min}, 25^{\circ} \mathrm{C}, 600 \mathrm{rpm}$. 
The effect of the acceptor phase volume on the amount of pyrethroid insecticides extracted was also examined. Two different volumes of hexane:acetone $(9: 1, \mathrm{v} / \mathrm{v})$, namely, 0.5 and $0.75 \mathrm{~mL}$, were tested (Table 1). Similar extraction efficiencies were acquired. However, at $0.5 \mathrm{~mL}$ solvent volume, the variation in the results largely increased. By contrast, this phenomenon was not observed when $0.75 \mathrm{~mL}$ of the solvent was used. The reason may be ascribed to the fact that the analytes are not exhaustively extracted by the $0.5 \mathrm{~mL}$ volume.

Effect of salt addition. The effect of the ionic strength on the MASE extraction efficiency has been previously reported, and salt addition enhanced the extraction yield of the polar compounds because of the salting-out effect. ${ }^{22}$ However, salt

Table 1 Optimization of the extraction solvent volume $(9: 1$ hexane: acetone, v/v) at $25^{\circ} \mathrm{C}$ and $600 \mathrm{rpm}$ (analyte concentration:10 $\mu \mathrm{g} \mathrm{L}^{-1}$ )

\begin{tabular}{|c|c|c|c|c|}
\hline \multirow[b]{3}{*}{ Pyrethroid insecticides } & \multicolumn{4}{|c|}{ Extraction solvent volume } \\
\hline & \multicolumn{2}{|l|}{$0.5 \mathrm{~mL}$} & \multicolumn{2}{|l|}{$0.75 \mathrm{~mL}$} \\
\hline & $\begin{array}{l}\text { Recovery } \\
(\%)\end{array}$ & RSD $(\%)$ & $\begin{array}{l}\text { Recovery } \\
(\%)\end{array}$ & $\operatorname{RSD}(\%)$ \\
\hline BIF & 72.9 & 14.3 & 83.0 & 8.8 \\
\hline PHE & 81.9 & 11.9 & 76.2 & 7.4 \\
\hline CYF & 77.4 & 9.8 & 91.4 & 6.7 \\
\hline CYP & 78.1 & 10.5 & 86.1 & 7.8 \\
\hline FEN & 74.0 & 11.9 & 80.4 & 8.4 \\
\hline DEL & 83.0 & 9.9 & 92.9 & 6.2 \\
\hline
\end{tabular}
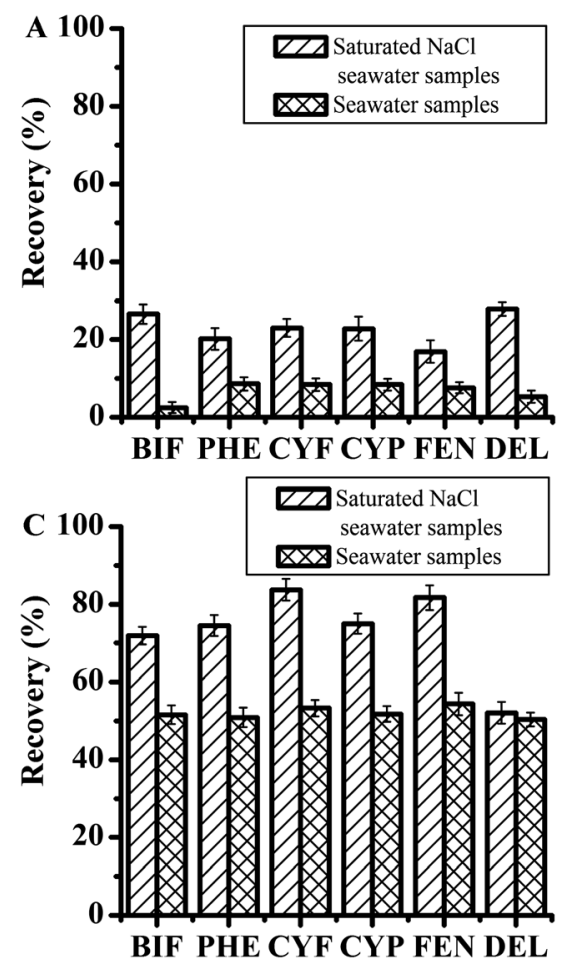

addition may also slightly reduce the extraction efficiency for non-polar compounds. ${ }^{23}$ Different effects of the ionic strength on the extraction yield can be obtained depending on the nature of the analytes. In the current study, acetone, which is a watermiscible solvent, acted as the acceptor phase of the hexane: acetone $(9: 1, \mathrm{v} / \mathrm{v})$ mixture. Phase separation plays a critical role in the extraction yield of MASE and can be largely enhanced by the addition of $\mathrm{NaCl}$ up to the saturation point. ${ }^{24}$ The results obtained are shown in Fig. 3. The presence of $\mathrm{NaCl}$ exhibited a significant effect on the extraction yield of the pyrethroid insecticides. Compared with the results obtained without the addition of $\mathrm{NaCl}$, the first extraction yield considerably increased, ranging between $17.7 \%$ and $30.4 \%$ for BIF, PHE, CYF, CYP, and FEN. For DEL, no significant difference was observed. On the basis of these results, further analysis of pyrethroid insecticides in seawater samples containing saturated $\mathrm{NaCl}$ was conducted.

Optimization of the stirring rate and the extraction time. To improve the transport of the pyrethroid insecticides through the MASE membrane, extraction vials containing the extraction membrane were stirred in the agitator at three stirring rates, namely, 300, 600, and $900 \mathrm{rpm}$. From 300 to $600 \mathrm{rpm}$, a distinct improvement in the extraction efficiencies for the six pyrethroid insecticides was observed; by contrast, only a slight increase in recovery was observed for DEL, whereas for rest of the pyrethroid insecticides it shown decrease in recovery at the 600 to $900 \mathrm{rpm}$ stirring rates (Fig. 4). Thus, $600 \mathrm{rpm}$ was selected and applied as the extraction stirring rate in subsequent analyses.
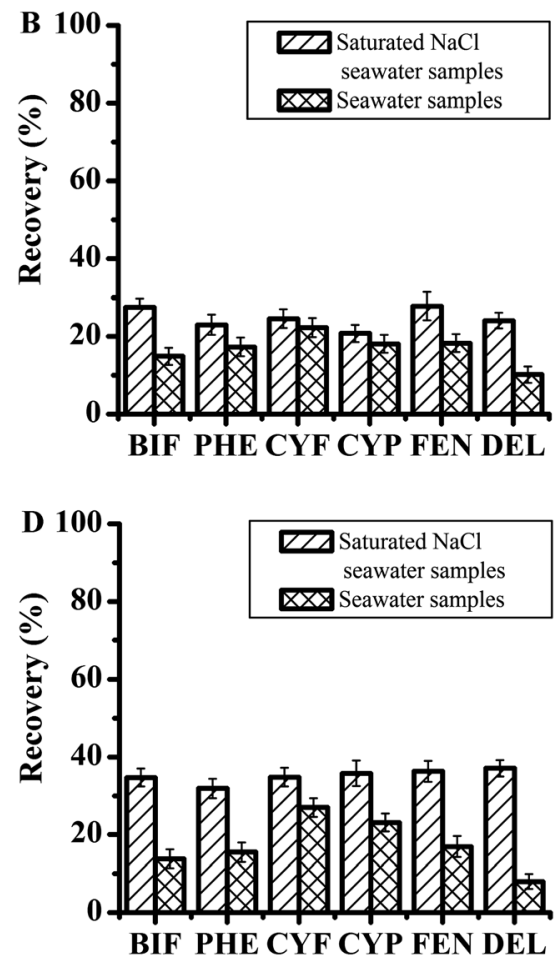

Fig. 3 Effect of saturated $\mathrm{NaCl}$ solution on the first extraction efficiency of MASE. Saturated $\mathrm{NaCl}$ seawater samples $(15.0 \mathrm{~mL})$ spiked with $10 \mu \mathrm{g} \mathrm{L}^{-1}$ of each analyte using (A) hexane; (B) cyclohexane; (C) hexane:acetone (9:1, v/v); and (D) cyclohexane:acetone ( $9: 1$, v/v) as extraction solvents. Extraction conditions: $60 \mathrm{~min}, 25^{\circ} \mathrm{C}, 600 \mathrm{rpm} ; n=3$. 


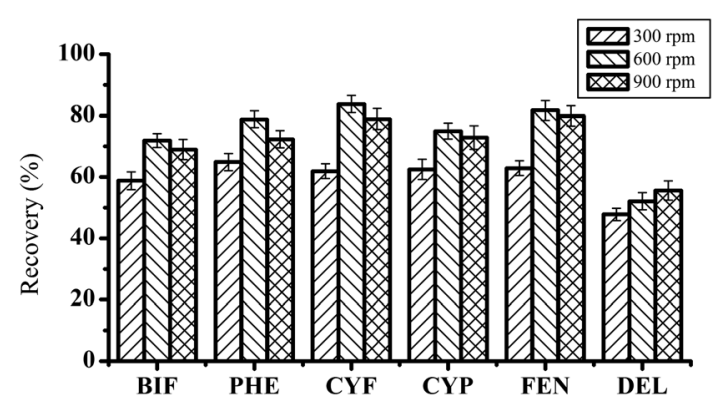

Fig. 4 Optimization of the stirring rate for MASE by evaluating the first extraction efficiency. Analyte concentration: $10 \mu \mathrm{g} \mathrm{L}^{-1}$; extraction conditions: $15.0 \mathrm{~mL}$ saturated $\mathrm{NaCl}$ seawater samples, $60 \mathrm{~min}, 25^{\circ} \mathrm{C}$; $n=3$.

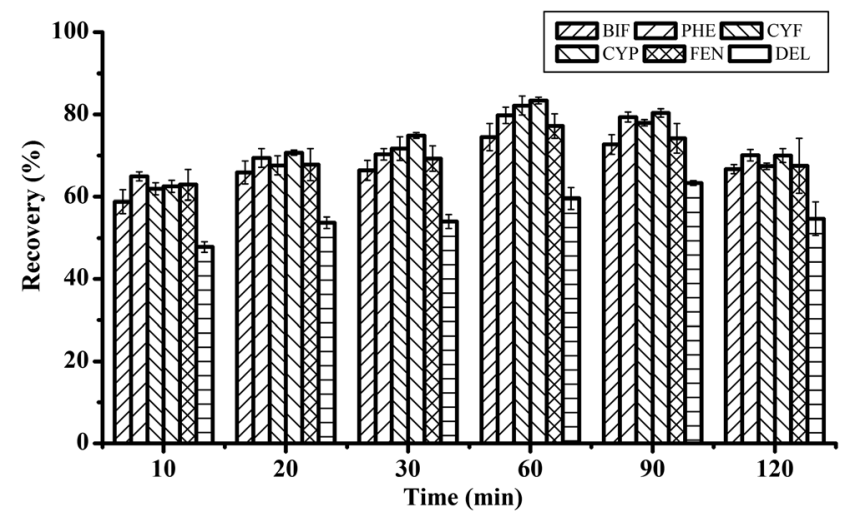

Fig. 5 MASE extraction time profile of the six pyrethroid insecticides at $25^{\circ} \mathrm{C}$ in $15.0 \mathrm{~mL}$ saturated $\mathrm{NaCl}$ seawater samples. Analyte concentration: $10 \mu \mathrm{g} \mathrm{L}^{-1}$; extraction conditions: $600 \mathrm{rpm} ; n=3$.

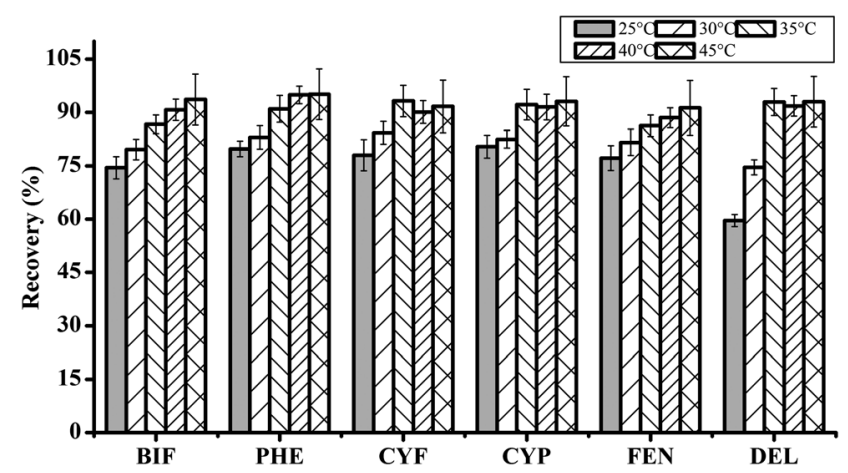

Fig. 6 MASE extraction temperature profiles of the six pyrethroid insecticides. Extraction conditions: $15 \mathrm{~mL}$ saturated $\mathrm{NaCl}$ seawater samples, $60 \mathrm{~min}, 600 \mathrm{rpm}$; analyte concentration: $10 \mu \mathrm{g} \mathrm{L}^{-1} ; n=3$.

The extraction time in the range of 10 to $120 \mathrm{~min}$ was also investigated. The results are shown in Fig. 5. The equilibrium was expected to be reached at $60 \mathrm{~min}$. A significant increase in the extraction efficiency from 10 to $60 \mathrm{~min}$ was observed. After 60 min, the equilibrium appeared to be nearly attained, and the extraction efficiency even decreased. The highest extraction recoveries for the six pyrethroid insecticides were obtained at the $60 \mathrm{~min}$ extraction time; therefore, $60 \mathrm{~min}$ was chosen as the optimum extraction time.
Optimization of the extraction temperature. The extraction temperature was optimized to further improve the first extraction efficiencies. The boiling points of hexane and acetone are 69 and $56{ }^{\circ} \mathrm{C}$, respectively; thus, a lower extraction temperature, between 25 and $45^{\circ} \mathrm{C}$, was studied using $15.0 \mathrm{~mL}$ seawater samples spiked with $10 \mu \mathrm{g} \mathrm{kg}^{-1}$ pyrethroids and extracted for 60 min at a stirring rate of $600 \mathrm{rpm}$. Fig. 6 shows that the best results were obtained at $40{ }^{\circ} \mathrm{C}$, with an RSD below $7.9 \%$. Although relatively high recoveries were obtained at $45{ }^{\circ} \mathrm{C}$, the reproducibility was significantly decreased (RSD $>10.4 \%$ ) because of the significant change in the extraction solvent volume after agitation at $45{ }^{\circ} \mathrm{C}$. Therefore, to ensure the optimal extraction reproducibility, $40{ }^{\circ} \mathrm{C}$ was chosen as the extraction temperature for the subsequent experiments.

\section{Validation of the procedure}

MASE provides a simple and effective method of extraction and enrichment of analytes from aqueous samples. In the current study, aquaculture seawater sample analysis was performed using the following parameters: $40^{\circ} \mathrm{C}$ extraction temperature, 60 min extraction time, addition of saturated $\mathrm{NaCl}$ solution, $0.75 \mathrm{~mL}$ extraction volume, and hexane:acetone $(9: 1, \mathrm{v} / \mathrm{v})$ as the extraction solvent. The developed MASE method was evaluated via quantitative analysis based on the linearity, LOD, LOQ, precision, accuracy, and extraction efficiency.

The linearity was evaluated by extracting the spiked seawater samples containing 1.0, 2.5, 5, 7.5, and $10 \mu \mathrm{g} \mathrm{L}^{-1}$ of FEN, DEL, CYP, CYF, and BIF, and 10, 25, 50, 75, and $100 \mu \mathrm{g} \mathrm{L}^{-1}$ of PHE. A good linearity for the six pyrethroid insecticides was obtained. The correlation coefficient $\left(R^{2}\right)$ of the calibration curve was higher than 0.9896 (Table 2).

The accuracy and precision of the developed MASE method were evaluated by determining the recovery and relative standard deviation (RSD) for three different concentrations of the six pyrethroid insecticides. The results are summarized in Table 3. Compared to the Florisil-SPE method, the mean quantitative recoveries of the six pyrethroid insecticides using MASE were highly improved and in the range of $85.9 \%-105.9 \%$, with RSD values $<7.9 \%$. These results demonstrate the good accuracy and precision of MASE coupled with GC-ECD for the determination of the six pyrethroid insecticides in aquaculture seawater samples. In addition, the extraction time and organic solvent consumption of MASE was considerably lower. Under optimum extraction conditions, the LOD $(\mathrm{S} / \mathrm{N}=3)$ and LOQ $(\mathrm{S} / \mathrm{N}=10)$ for the six pyrethroids were in the 0.037-0.166 and $0.12-0.55 \mu \mathrm{g} \mathrm{L}^{-1}$ ranges, respectively (Table 2). However, the sensitivity of the proposed method for PHE was considerably decreased compared with the other pyrethroids because of the absence of halogen atoms in its molecular structure. ${ }^{25}$ Matrix effects during the application of the proposed method were assessed by comparing the calibration curves and the GC-ECD chromatograms of the MASE-extracted samples in pure water and in the aquaculture seawater spiked with standard solutions of pyrethroid insecticides (Fig. 7, Table 2). Small differences in the obtained analytical curves were observed, and the chromatograms did not show obvious interference of other compounds, indicating no obvious matrix effect. These results also indicate the potential applicability and sensitivity of the 
Table 2 MASE validation data

\begin{tabular}{|c|c|c|c|c|c|}
\hline Pyrethroid pesticides & $\begin{array}{l}\text { Linear range } \\
\left(\mu \mathrm{g} \mathrm{L}^{-1}\right)\end{array}$ & $R^{2^{a}}$ & $R^{2^{b}}$ & $\operatorname{LOD}\left(\mu \mathrm{g} \mathrm{L}^{-1}\right)^{c}$ & $\begin{array}{l}\mathrm{LOQ} \\
\left.\mathrm{L}^{-1}\right)^{d}\end{array}$ \\
\hline BIF & $1-10$ & 0.9918 & 0.9929 & 0.0636 & 0.21 \\
\hline CYF & $1-10$ & 0.9934 & 0.9949 & 0.0369 & 0.12 \\
\hline CYP & $1-10$ & 0.9939 & 0.9957 & 0.0392 & 0.13 \\
\hline FEN & $1-10$ & 0.9900 & 0.9915 & 0.0432 & 0.14 \\
\hline DEL & $1-10$ & 0.9931 & 0.9951 & 0.0721 & 0.24 \\
\hline
\end{tabular}

${ }^{a}$ Linearity for MASE in the aquaculture seawater samples. ${ }^{b}$ Linearity for MASE in pure water. ${ }^{c} \mathrm{~S} / \mathrm{N}$ ratio $=3 .{ }^{d} \mathrm{~S} / \mathrm{N}$ ratio $=10$.

Table 3 Recoveries (\%) and RSD (\%) of the analytes in aquaculture seawater samples after extraction and enrichment by MASE and Florisil-SPE coupled with GC-ECD $(n=3)$

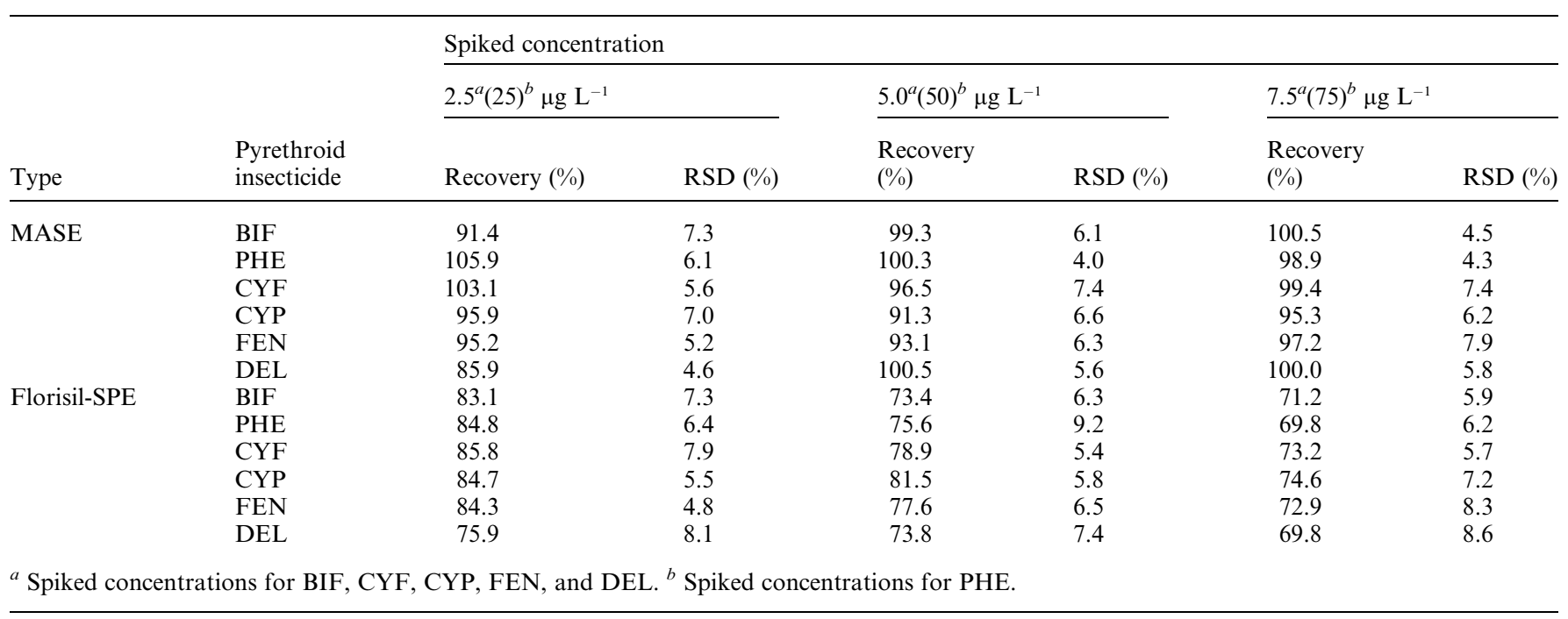

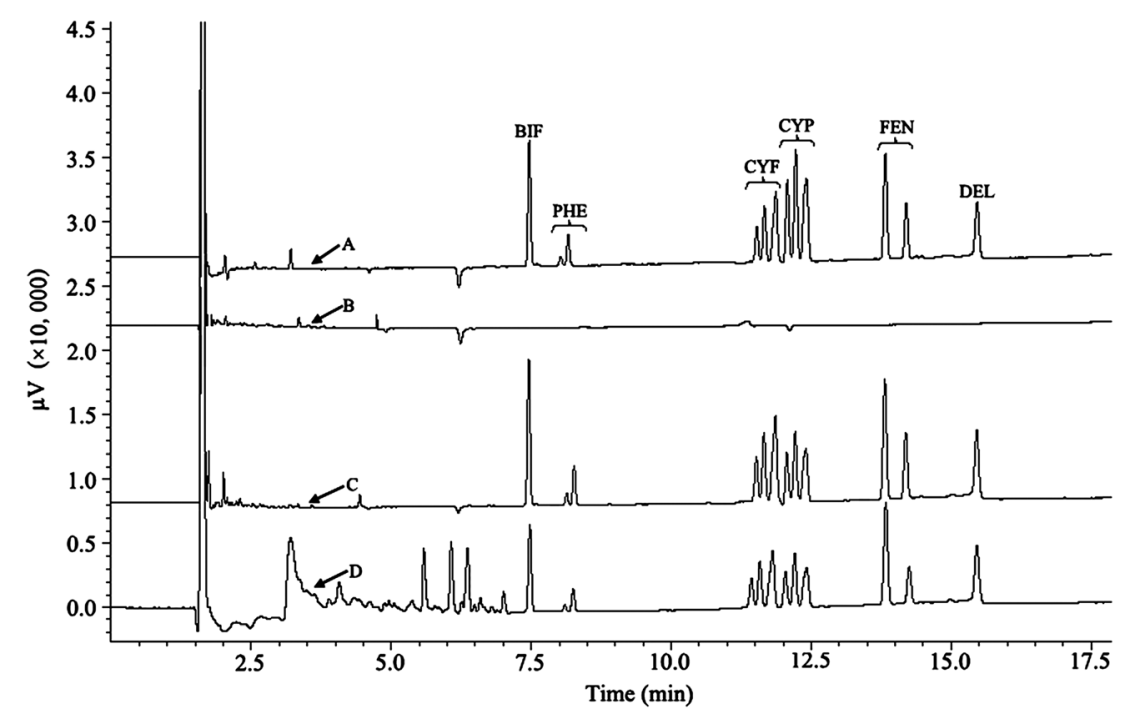

Fig. 7 Chromatographic profiles of $15.0 \mathrm{~mL}$ seawater samples spiked with $5.0 \mu \mathrm{g} \mathrm{L}{ }^{-1}$ each of BIF (7.474 min), CYF (11.021 min, $11.158 \mathrm{~min}, 11.361$ $\mathrm{min}$ ), CYP (11.568 min, $11.716 \mathrm{~min}, 11.908 \mathrm{~min}$ ), FEN (13.175 min, $13.550 \mathrm{~min}$ ), and DEL (14.627 min) and $50 \mu \mathrm{g} \mathrm{L}{ }^{-1}$ of PHE (8.034 min, $8.167 \mathrm{~min}$ ) after MASE and Florisil-SPE. (A) Reference standard; (B) blank sample; (C) spiked saturated seawater samples after MASE; and (D) spiked seawater samples after Florisil-SPE. 
MASE method coupled with GC-ECD in the quantitative determination of pyrethroid insecticides in aquaculture seawater samples.

\section{Conclusion}

A novel analytical method based on the MASE method coupled with GC-ECD was developed for the simultaneous analysis of six pyrethroid insecticides in aquaculture seawater samples. Compared with LLE and Florisil-SPE, the developed MASE method has a lower organic solvent and time consumption. Given the simplicity of the MASE extraction procedure, high sample throughput can be achieved by parallel sample processing. Moreover, the first extraction yield of MASE was considerably improved by optimizing the parameters. The optimized MASE procedure was successfully applied to the analysis of pyrethroid insecticides in aquaculture seawater samples. Furthermore, because of the use of hexane: acetone $(9: 1, \mathrm{v} / \mathrm{v})$ as the acceptor solvent, the extraction solvent obtained after MASE can be directly injected to the GC-ECD. The extraction procedure based on MASE coupled with the GC injection process shows great potential for the automated determination of pyrethroid insecticide residues in aquaculture seawater environments.

\section{Acknowledgements}

This study was funded by the Social Development Fund of the Science and Technology Department of Zhejiang Province (2010C33054), the Natural Science Foundation of Ningbo (2009A610146), the National Natural Science Foundation of China (31001139), Ningbo Science and Technology Bureau (2009C50028), the Specialized Research Fund for the Doctoral Program of Higher Education (20103305120001), the Scientific Research Fund of Ningbo University (xk111101), and the K. C. Wong Magna Fund of Ningbo University.

\section{References}

$1 \mathrm{H}$. Bailey, L. Deanovic, E. Reyes, T. Kimball, K. Larson, K. Cortright, V. Conner and D. E. Hinton, Environ. Toxicol. Chem., 2000, 19, 82.

2 A. Francesc, E. Turrillas, A. Pastor and M. D. L. Guardia, Anal. Chim. Acta, 2005, 553, 50.

3 D. L. Wang, D. P. Weston and M. J. Lydy, Talanta, 2009, 78, 1345.

4 F. J. Arrebola, J. L. Martínez-Vidal, A. Fernández-Gutiérrez and M. H. Akhtar, Anal. Chim. Acta, 1999, 401, 45.

5 J. You, D. Wang and M. J. Lydy, Talanta, 2010, 81, 136.

6 A. Mekebri, D. B. Crane, G. J. Blondina, D. R. Oros and J. L. Rocca, Bull. Environ. Contam. Toxicol., 2008, 80, 455.

7 S. S. Albaseer, R. N. Rao, Y. V. Swamy and K. Mukkanti, J. Chromatogr., A, 2010, 1217, 5537.

8 S. Zawiyah, Y. B. Che Man, S. A. H. Nazimah, C. K. Chin, I. Tsukamoto, A. H. Hamanyza a and I. Norhaizan, Food Chem., 2007, 102, 98.

9 J. Wu, J. Lu, C. Wilson, Y. Lin and H. Lu, J. Chromatogr., A, 2010, $1217,6327$.

10 M. L. Feo, A. Ginebreda, E. Eljarrat and D. Barceló, J. Hydrol., 2010, 393, 156.

11 P. Serôdio and J. M. F. Nogueira, Anal. Bioanal. Chem., 2005, 382, 1141.

12 H. P. Li, C. H. Lin and J. F. Jen, Talanta, 2009, 79, 466.

13 M. I. Pinto, G. Sontag, R. J. Bernardino and J. P. Noronh, Microchem. J., 2010, 96, 225.

14 J. Regueiro, M. Llompart, C. Garcia-Jares, J. C. Garcia-Monteagudo and R. Cela, J. Chromatogr., A, 2008, 1190, 27.

15 N. Ochiai, K. Sasamoto, H. Kanda and E. Pfannkoch, $J$. Chromatogr., A, 2008, 1200, 72.

16 V. Casas, M. Llompart, C. García-Jares, R. Cela and T. Dagnac, J. Chromatogr., A, 2006, 1124, 148.

17 B. Hauser, P. Popp and E. Kleine-Benne, J. Chromatogr., A, 2002, 963, 27.

18 M. Schellin, B. Hauser and P. Popp, J. Chromatogr., A, 2004, 1040, 251.

19 Z. Szekeres, Z. Eke, T. Rikker and K. Torkos, J. Chromatogr., A, 2009, 1216, 6964.

20 M. Schellin and P. Popp, J. Chromatogr., A, 2005, 1072, 37.

21 F. G. Ye, Z. H. Xie, X. P. Wu and X. C. Lin, Talanta, 2006, 69, 97.

22 J. G. March, F. Moukhchan and V. Cerdà, Anal. Chim. Acta, 2011, 685, 132

23 L. Chimuka, M. van Pinxteren, J. Billing, E. Yilmaz and J. Å Jönsson, J. Chromatogr., A, 2011, 1218, 647.

24 J. B. Quintana and T. Reemtsma, J. Chromatogr., A, 2006, 1124, 22.

25 M. L. Feo, E. Eljarrat and D. Barceló, J. Chromatogr., A, 2010, 1217, 2248. 